\title{
La fuerza de la educación para una cultura de paz
}

Aprobado:

15 de febrero de 2020 Recibido: 28 de febrero de 2019 DOI: http://dx.doi.org/10.18566/rfts.v33n33.a04

\section{Omar Arango Otálvaro}

Omar Arango Otálvaro. Sociólogo. UNAULA. Magister en Educación. UdeA. Profesor titular Centro de Humanidades UPB. 


\section{Resumen}

La guerra es inevitable, de allí la importancia de desarrollar su contrario mediante la educación; esto es, con valores éticos. La convicción de que la educación es uno de los caminos que hace posible la paz debe materializarse en un conjunto de disposiciones que la reglamenten en una cátedra que promueva una cultura de paz y la convivencia con respeto. Es la lección por aprender la paz como un fin en sí mismo y la educación como medio, cuya justa defensa no puede ser la guerra, pues no sería coherente buscar la paz mediante las atrocidades de la guerra. En la educación para una cultura de paz debe intervenir la naturaleza humana que geste la oportunidad de defender el derecho a la vida; de allí derivaría la convicción de que "la paz es un derecho y un deber de obligatorio cumplimiento".

Palabras clave

Paz, Educación, Cátedra, Guerra, Ética, Deber.

\section{Abstract}

War is inevitable, hence the importance of developing its opposite through education, that is, with ethical values. The conviction that education is one of the paths that makes peace possible must be embodied in a set of provisions that regulate it in a chair that promotes a culture of peace and coexistence with respect.

It is the lesson to be learned, peace as an end in itself and education as a means, whose just defense cannot be war, because it would not be coherent to seek peace through the atrocities of war. In education for a culture of peace, human nature must intervene to manage the opportunity to defend the right to life; from there would derive the conviction that "peace is a right and a duty of obligatory fulfillment".

Key words

Peace, Education, Cathedra, War, Ethic, Obligation. 


\section{Marco histórico y contextual}

La guerra es un medio inconveniente de resolver los conflictos sociopolíticos de Estado o entre Estados en relación con el poder o disputas territoriales deviniendo en el mayor conflicto de Estado; sin embargo, no debe confundirse con el conflicto popularizado por los convenios de Ginebra. El conflicto comprende la guerra y lo trasciende al aludir a las luchas con armas entre grupos o revueltas internas donde no necesariamente media una declaración formal de guerra. Predicando con el ejemplo, la lucha contra el Eln y, otros reductos guerrilleros y demás grupos armados en Colombia es una buena ilustración de lo que es un conflicto armado.

El mundo de hoy es inseguro. Desde la segunda postguerra no hemos tenido veinticuatro horas de paz. De 1945 al presente, hemos tenido unos 150 conflictos de diferente naturaleza e intensidad que han causado 20 millones de muertos. La última guerra mundial produjo 50 millones de víctimas. Asia y África son los continentes más afectados por las guerras: guerras ofensivas, defensivas, de insurrección, revolución, independencia, guerras religiosas, civiles, de conquista, coloniales, de intervención, guerras nacionales, mundiales, sucias, y muchos etcéteras.

Las guerras ofensivas y defensivas son formas de lucha armada y política en las que un Estado ataca a otro que resiste su destrucción o algún tipo de sometimiento ideológico o de otro orden, dentro del que puede encontrarse una disputa de tipo territorial. La insurrección es un levantamiento contra el poder dominante en su sentido más general, revestido de un carácter político para destituir un gobierno, pero también puede estar orientada a deponer el bloque constitutivo en el poder o la autoridad del Estado. La revolución, está muy asociada a las guerras civiles, o de independencia, donde uno de los actores se conoce como ejército revolucionario. Para Marcel Clement (1973), este tipo de guerra pretende provocar el derrocamiento del orden establecido en un país, y su sustitución por una tendencia ideológica opuesta.

Las guerras de independencia se relacionan con un objetivo concreto: la liberación de un territorio. Religiosas, llamadas santas o justas, son guerras que tienen como factor principal a la religión, frente a la cual, los actores ostentan posiciones diferentes con una salida violenta. Civil, es una guerra que se produce en un mismo país en el que se confrontan ideologías distintas 
con visiones políticas también distintas como intereses, que puede conducir a secesiones territoriales. Conquista y colonial, según algunas fuentes son un tipo de conflicto colonial, bélico, por la disputa del control de un territorio (la colonia) caracterizado por su inferior desarrollo.

De intervención, cuando una o varias potencias participan en una guerra civil con el propósito de favorecer a una de las partes, y también para extender el conflicto y desde luego, generar la derrota al oponente. Nacional, es una forma de conflicto entre dos o más grupos connacionales con diversos tipos de propósitos tendientes al control del poder o el cambio de relaciones de poder.

Las guerras mundiales, son un conflicto armado a gran escala que compromete a varias naciones de un mismo continente o de continentes distintos. Sucia, los analistas la toman como terrorismo de Estado; quiere decir, la acción permanente que los aparatos represivos del Estado como el ejército y la policía ejercen contra grupos e incluye la violencia, desapariciones, tortura, violación de los derechos humanos, cárceles clandestinas, entre otras.

Igualmente, están las guerras de primera generación; así, por ejemplo, las de independencia hispanoaméricana o las napoleónicas; de segunda generación, como la Primera Guerra Mundial o la guerra Irán-Irak; de tercera generación, como la guerra del golfo o la guerra de Corea y de cuarta generación, como el conflicto armado en Colombia o la guerra contra el terrorismo.

Según William S. Lind (2005), las guerras de primera generación se desarrollaron entre 1648 y 1860, en donde sobresalía "el orden en el campo de batalla" y se "creó una cultura de orden militar" (p. 12). Las de segunda generación se distinguen por su forma de "potencia de fuego en masa" (p. 13). Las de tercera generación no se basan en la potencia, sino en la velocidad, y se les llama guerras relámpago o de maniobra. Las de cuarta generación están caracterizadas "por un retorno al mundo de culturas, y no simplemente estados en conflicto", en donde Estados se enfrentan a actores armados y oponentes no estatales como Al-Qaeda, Hamas" (p. 14), entre otros, y por las guerras o conflictos armados que tienen en su origen una "crisis universal de legitimidad del estado", que significa que en algunos países se presenten confrontaciones en su propio territorio" y entre sus ciudadanos (p. 14). 
Los conflictos se ubican en todos los lugares del planeta. Oriente medio y el África negra son las zonas donde tenemos más conflictos en curso. Son once conflictos los que hacen inseguro al mundo hoy: la insurgencia de Al-Qaeda en Yemen; la presencia de Boko Haram en Níger; Isis controla algunas áreas entre Siria e Irak; Hamás en oriente medio es el enemigo más recalcitrante de Israel; la República Democrática del Congo es atacada por supuestos grupos terroristas no identificados; los milicianos en el este de Ucrania desestabilizan varias zonas; en Siria los grupos rebeldes luchan contra el gobierno de $\mathrm{Al}$ Asad; en la guerra civil sursudanesa una facción del ejército se enfrenta por la liberación del pueblo de Sudán luchando contra el régimen; la guerra en Libia se enmarca en la lucha por el control del país y contra los yihadistas; con la llegada al poder del grupo Seleka en la república centro africana lo que era la paz entre cristianos y musulmanes se vio alterada.

En los últimos 48 años han ocurrido 240 conflictos internos y 22 enfrentamientos entre países en todo el mundo. Estos se deben a diferencias étnicas, a ocupación de territorios o a intereses políticos. Lo común de estos conflictos es su carácter interno. Un buen número se presentan en el hemisferio sur. Aquí se torturan y someten a la violación de los derechos humanos a los presos de conciencia. Tenemos dos cárceles ignominiosas: Abu Grahib, en Irak y Guantánamo, en Cuba. Se utilizan armas químicas, biológicas y bacteriológicas que traen enfermedades, contaminan las aguas y los alimentos, lo que constituye una abierta violación al Derecho Internacional Humanitario.

Según la Organización de las Naciones Unidas (ONU), en un informe publicado en 2019, los muertos que dejaron los diferentes conflictos armados para 2017 alcanzaron la impresionante cifra de más de 370.000 (párr. 1). Otros datos revelarían que la guerra civil en Siria "entre 2011 y 2018 ", ha interrumpido la vida de poco más de 500.000 seres humanos y la huida de más del 40\% de su población que busca refugio en Europa (Sancha, 2018, párr. 1). En Ucrania del este, desde 2013 a 2019, más de 10.000 personas han encontrado la paz en el sepulcro (La Vanguardia, 2019, párr. 1). En Afganistán, en 18 años de conflicto (2000-2018), aproximadamente 147.000 civiles han sido sorprendidos por la obscuridad (Pinna, 2019, párr. 1). En Sudán del Sur, entre 2013 y 2019, aproximadamente 385.000 ciudadanos 
fueron asesinados (Aragó, 2019, párr. 4). En la República del Congo, para 2018, 3.8 millones de personas requerían ayuda humanitaria, con el agravante que de ellos 2,3 millones eran niños (Unicef, 2018, párr. 3). En Nigeria, la confrontación de las fuerzas armadas con el grupo islamista Boko Haram, desde 2004 a 2018, ha dejado la muerte de 30.000 civiles (Aragó, 2019, párr. 16). Colombia ha sacrificado 220 mil personas; sin embargo, si se suman el resto de las personas que han sufrido con otras acciones por cuenta del conflicto armado, y según la oficina de la unidad de víctimas, la cifra total supera los 9 millones de colombianos (Unidad para la atención y reparación integral a las víctimas, 2019, párr. 1).

A propósito de lo que se viene señalando, Camps (1994) expresa:

La guerra se hace siempre en defensa de instituciones, pueblos, naciones o ideas. Nunca en defensa de los individuos concretos. Sus razones pasan por encima de las atrocidades y los costos humanos y económicos, que la guerra comporta. La industria armamentística es ya una parte imprescindible de la organización política y económica de todas las naciones (p. 124).

Sobre "el total del gasto militar mundial" hay que expresar como este "llegó hasta los 1,7 billones de dólares en 2017", donde "solo Estados Unidos gastó US\$610.000 millones en 2017 (BBC News, 2018, párr. 1).

El conflicto político existente en Colombia tiene sus antecedentes históricos en el siglo XIX con las guerras civiles que enfrentaron a los liberales con los conservadores. Tiene como hecho la Guerra de los mil días (en realidad, de 1130 días), entre el $17^{\circ}$ de octubre de 1899 y el 21 de diciembre de 1902 , año este último en el que se realizó el tratado de paz definitivo que se firmó a bordo del acorazado estadounidense USS Winsconsin. Otras guerras que se presentaron durante el siglo XIX fueron: centralistas y federalistas (1812- 1815); Guerra de los supremos (1839-1841); guerra civil de 1851; guerra civil de 1854; guerra civil de 1860-1862; guerra civil de 1884-1885 y guerra civil de 1895 .

Pueden entenderse estas guerras como el primer estadio del conflicto armado en Colombia. Un segundo estadio se presenta a comienzos del siglo XX con la aparición de diferentes organizaciones políticas como el partido 
socialista revolucionario y el partido comunista colombiano que respaldaron algunas revoluciones campesinas. La violencia bipartidista que enfrentó a los partidos políticos liberal y conservador es un tercer estadio que da comienzos hacia los años 30 con la república liberal de Enrique Olaya Herrera y alcanza su máxima expresión con el asesinato de Jorge Eliécer Gaitán en 1948 y la rebelión espontánea del "bogotazo" como consecuencia.

Otros hechos conexos están relacionados con este tercer estadio como son la aparición de las guerrillas, la república conservadora y el Frente Nacional. El cuarto estadio y último, o de la violencia revolucionaria, comienza hacia los años 60 y se extiende hasta el presente. Es el estadio de la confrontación total del Estado por organizaciones revolucionarias de inspiración marxista, leninista y maoísta que aparecieron en la década de los 60, como las FARC y el ELN en 1964, y el EPL en 1965.

\section{Marco conceptual}

Parafraseando a Zorro Sánchez (2010, párr. 5), la política debe promover la inserción de una ética humanista en la concepción y la práctica de los grandes fines sociales con un enfoque de interculturalidad al que debe dirigirse la promoción de una cultura de paz; de otro lado, debe suscitar "la transformación civilizatoria de una cultura de violencia a una cultura de paz" (Prera Flores, 1997, p. 2), o lo que es igual, fomentar "la dimensión práctica del derecho humano a la paz” (p. 2), y no sólo la política; el Estado debe promocionar el derecho de los pueblos a la paz y su puesta en práctica.

Prera Flores (1997), considera que este derecho se hace posible rescatando "el sentido ético de la vida y respetando los derechos del otro" (p. 5), mediante el desarrollo de las competencias ciudadanas dirigidas a los niños, padres de familia, maestros y otros, respetuosos de las diferencias, bien sean estas de creencias, convicciones, ideológicas o cualquier otra experiencia particular, para ejercer el deber de vivir en paz y respetar el derecho a la vida.

Desde esta perspectiva, tanto para el Estado como para la política, "la primera ley de la naturaleza debe ser buscar la paz y mantenerla"(Camps, 1994, p. 122); en otros términos, "la paz como algo que debe ser instaurado"(Camps, 1994, p. 123), pero también en las aspiraciones de la política y el Estado como algo 
esencial debe actuar el respeto por los derechos de las minorías y el diálogo de las culturas; de ahí que la promoción de la interculturalidad debe hacer posible legitimar la política y el Estado democrático; quiere decir, independiente de cualquier categoría de interés en un mundo en el que la interculturalidad y la convivencia armónica entre culturas diferentes no está totalmente asumida.

Esto es humanismo consciente; una fuerza orientada a resolver los problemas de "cohesión de la sociedad sobre la base de los valores del humanismo" (Prera Flores, 1997, p.3) y los valores contenidos en la declaración de los derechos humanos.

¿Qué objetivos tiene o desarrolla este texto? En consonancia con la Unesco, primero, reconocer instrumentos para aplicar el derecho humano a la paz con mecanismos jurídicos; segundo, con el espíritu de la conferencia mundial sobre derechos humanos de Viena, de 1993, acoger su declaración final sobre la importancia de la educación en la promoción de la paz, en particular, el párrafo 33 de la sección I; tercero, valorar la visión de los agentes sociales al desarrollar planes concretos y pautas generales sobre lo conveniente de la reconciliación como el programa "soy capaz".

Como resultado esperado, cuarto, presentar la Ley 1732 del $1^{\circ}$ septiembre de 2014, por la cual se establece la cátedra de la paz en todas las instituciones educativas de Colombia, y el decreto número 1038 de mayo 25 de 2015, por el que se reglamenta dicha cátedra; ambos como elementos normativos concretos para comprender su relación con los estándares de competencias básicas y ciudadanas, y con la Ley 1620 de convivencia escolar de 2013, de acuerdo con un enfoque de interculturalidad y desarrollo sostenible; por último, valorar el proyecto de ordenanza \# 10 por medio del cual se crea la gerencia de paz y posconflicto para Antioquia por parte de la Asamblea departamental de Antioquia.

\section{Marco normativo: el contexto colombiano}

Colombia es un país con un conflicto interno tan antiguo como la máquina a vapor o el telar de hilar. El gobierno de Juan Manuel Santos (2010-2018) se propuso encontrarle una salida política mediante la negociación de una agenda que contenía cinco puntos: política de desarrollo agrario integral; 
participación política; fin del conflicto; solución al problema de las drogas ilícitas; y víctimas y verdad. El proceso se llevó a cabo en dos fases: la primera, en Oslo (octubre de 2012) y la segunda, en La Habana (noviembre de 2012 a junio de 2016). Por otra parte, los políticos trabajaron en una ley cuya finalidad era la de definir disposiciones sobre el derecho a la paz.

Así, pues, mediante la Ley 1732 del $1^{\circ}$ de septiembre de 2014, los congresistas establecieron la cátedra de la paz como una iniciativa que busca promover la enseñanza de la paz en la educación básica y superior y la formación en materia de derechos humanos y resolución de conflictos, teniendo como contexto el proceso de negociación que se llevó a cabo en Cuba. No obstante, la cátedra de la paz trasciende los diálogos de La Habana.

Se concibió y fundamentó, antes de la firma final del conflicto entre el gobierno y los actores del conflicto armado, según el artículo 2 de la ya citada Ley 1732, "para corresponder al mandato constitucional consagrado en los artículos 22 y 41 de la constitución nacional" (Congreso de Colombia, 2014), confiriéndole el carácter de obligatorio y para dar respuesta por otro lado, a la inmoralidad de la violencia, a la historia del maltrato y la vuelta permanente a la agresión.

Pero, ¿qué es la cátedra de la paz? Es la promoción de una cultura de paz y de los derechos humanos en la infancia, la adolescencia y la juventud, a lo que debe sumársele la formación, la protección y la promoción en familias $\mathrm{y}$ escuelas $\mathrm{u}$ otros actores sociales con un enfoque de interculturalidad y desarrollo sostenible. El artículo 1 de la Ley 1732 lo enuncia así: "Con el fin de garantizar la creación y el fortalecimiento de una cultura de paz en Colombia, establézcase la cátedra de la paz en todas las instituciones educativas de preescolar, básica y media como una asignatura independiente" (Congreso de Colombia, 2014).

¿Cuál es su objetivo? En el parágrafo 2 del artículo 1 de la ley 1732 el Congreso de Colombia decreta:

La cátedra de la paz tendrá como objetivo crear y consolidar un espacio para el aprendizaje, la reflexión y el diálogo sobre la cultura de la paz y el desarrollo sostenible que contribuya 
al bienestar general y el mejoramiento de la calidad de vida de la población (2014).

La cátedra, en el parágrafo 3 del artículo 1, se define como "un espacio de reflexión y formación en torno a la convivencia con respeto, fundamentado en el artículo 20 del pacto internacional de derechos civiles y políticos" (Congreso de Colombia, 2014), que afirma en el numeral 1 como "toda propaganda en favor de la guerra estará prohibida por la ley”. Asimismo, el numeral 2 señala que "toda apología del odio nacional, racial o religioso que constituya incitación a la discriminación, la hostilidad o la violencia estará prohibida por la ley".

En el plan decenal de educación 2006 - 2016, a partir del artículo 14 de la Ley general de educación de 1994, y reglamentado en el decreto 1860 del mismo año y modificado por las leyes 1013 y 1029 de 2006, se definió que además de las áreas obligatorias, los establecimientos debían impartir formación en la educación para la paz, la justicia, la democracia, la solidaridad, el cooperativismo y en general, la formación de los valores humanos.

El plan decenal en el capítulo 1, “desafíos de la educación en Colombia”, tiene como tema: educación en y para la paz, la convivencia y la ciudadanía. Define 5 macro objetivos, 45 objetivos, 6 macrometas, 59 metas y 97 acciones. Para nuestro propósito, solamente se enuncian los 5 macro objetivos dado su interés: 1. Inclusión, diversidad, diferencia, identidad y equidad; 2 . Otros agentes educativos y relaciones con el entorno; 3 . Educación en valores, participación y convivencia democrática; 4 . Estructura y organización escolar; 5. Derechos, protección, promoción y población vulnerable con necesidades educativas especiales (Ministerio de educación, 2006, pp. 24-25).

El parágrafo 1 del artículo 1 de la Ley 1732, en lo atinente al desarrollo de la cátedra en la educación superior, señala que en "observancia del principio de autonomía universitaria, cada institución de educación superior desarrollará la cátedra de la paz, en concordancia con sus programas académicos y su modelo educativo" (Congreso de Colombia, 2014); a lo que el decreto reglamentario 1038 de 2015 establece la responsabilidad de definir los contenidos curriculares, lo cual dependerá del nivel académico y de formación de sus programas, la orientación filosófica plasmada en sus estatutos, y del perfil que hayan diseñado para sus egresados, entre otros aspectos. 
En 2015, el gobernador Luis Pérez Gutiérrez solicitó a la Asamblea Departamental la creación de la gerencia de paz y posconflicto bajo el argumento de consolidar los procesos de pacificación y reconciliación en los municipios antioqueños.

En este orden de significaciones, la Asamblea Departamental mediante el proyecto de ordenanza \# 10, creó la gerencia de paz y posconflicto con funciones muy específicas, en consonancia con los artículos 2 y 22 y los principios, derechos y deberes consagrados en la Constitución Política de 1991.

\section{Marco operativo}

El Estado, los educadores y la sociedad saben que educar para la paz es una tarea que no brinda resultados claros e inmediatos. Aun así, los parlamentarios colombianos han trabajado en aprobar una ley sobre cómo educar para la paz que contenga unas disposiciones sobre este derecho.

En efecto, el decreto 1038 de 2015, en su artículo 2 afirma que:

La cátedra de la paz deberá fomentar el proceso de apropiación de conocimientos y competencias relacionados con el territorio, la cultura, el contexto económico y social y la memoria histórica, con el propósito de reconstruir el tejido social, promover la prosperidad general y garantizar la efectividad de los principios, derechos y deberes consagrados en la constitución (Ministerio de Educación Nacional, 2015).

Esta es la joya de la corona de toda la normatividad de la cátedra. Son varias las razones para afirmarlo. En primer término, el tema de las competencias y el proceso de apropiación de conocimientos. La exministra de Educación nacional Cecilia María Vélez White, en una carta abierta sobre aprender en la convivencia escribió:

Estamos convencidos que la educación es uno de los caminos que hará posible la paz. Si abrimos las puertas de todas las escuelas y colegios [...] y brindamos educación de calidad [...] damos la oportunidad de vivir y construir un país en paz. 
Y continúa:

Desde el eje del mejoramiento de la calidad de la educación, contenido en el plan de desarrollo, hemos venido trabajando, en conjunto con maestros, catedráticos, académicos y profesionales de las más diversas disciplinas, en la formulación de unos estándares básicos que nos permitan desarrollar en nuestros niños no sólo las habilidades comunicativas, matemáticas y científicas... y tal vez lo más importante, competencias para ejercer los derechos y deberes de un buen ciudadano... unos ciudadanos que prefieran el acuerdo y el pacto, antes que las armas, para resolver conflictos (Ministerio de educación nacional, 2004, p. 1).

En estas circunstancias, las competencias para una cultura de paz en la educación como espacio específico para la formación ciudadana, deben construirse según "el sentido y vivencia de los valores ciudadanos, los derechos humanos, el derecho internacional humanitario, la participación democrática, la prevención de la violencia y la resolución pacífica de conflictos" (Presidencia de la República de Colombia, 2015, artículo 2). Por otra parte, las competencias de una educación para la paz en la escolaridad y, la escuela como espacio específico de formación ciudadana, deben construirse mediante la apropiación de conocimientos para ser más pacíficos en lo social, tolerantes y participativos en lo político, respetuosos de los derechos humanos y vivir en armonía la pluralidad.

Ahora bien, ¿̇cómo se ponen en marcha las competencias para una cultura y educación para la paz en la interacción entre los individuos y los grupos en la organización social? La respuesta no puede ser equivocada: se hace mediante la universalización; equivale a decir que los individuos y los grupos deben practicarlas en la incumbencia de sus roles confiriéndole su consentimiento; en otros términos, "que el ciudadano actúe de manera constructiva en la sociedad democrática" (Ministerio de Educación Nacional, 2004, p. 8) y de forma estable en sus interrelaciones funcionales con otras personas en búsqueda del bien común.

Esto no es de ahora, pero tuvo la exministra la visión hacia la cátedra de la paz, lo cual queda confirmado cuando el decreto 1038 "en su artículo 5" expresa que: "A partir de 2016, el Instituto Colombiano para la Evaluación de 
la Educación incorporará dentro de las pruebas saber 11, en su componente de competencias ciudadanas, la evaluación de los logros correspondientes a la cátedra de la paz”. (Ministerio de Educación Nacional, 2015)

En segundo término, promover la prosperidad general. El literal b del artículo 2 del decreto 1038 entiende la educación para la paz, en uno de sus razonamientos, como construcción de equidad. Esta entendida como la necesidad perentoria de no permitir desigualdades extremas que obstaculicen al ciudadano el desarrollo de las capacidades de influir políticamente y de ejercer su ciudadanía. En lo fundamental, eliminar los factores que impiden la transmisión de oportunidades de una generación a otra.

Tercero, el proceso de apropiación de competencias que fomentará la cátedra para la reconstrucción del tejido social hará posible que el ciudadano actúe de manera constructiva en la sociedad democrática mediante el desarrollo, de al menos dos temáticas, como lo establece el artículo 4 del decreto: así, por ejemplo, justicia y derechos humanos y dilemas morales; o diversidad y pluralidad e historia de los acuerdos nacionales e internacionales, entre otros.

La democracia no puede tener una gramática que se agote en el acceso de los ciudadanos a los cargos públicos: se extiende para asegurar la paz a los integrantes de la unidad de la nación. En tal sentido, la escuela debe propiciar valores y procesos necesarios para formar sujetos capaces de cumplir con las obligaciones y responsabilidades de la democracia; es decir, cumplir con los deberes como el de la paz y el ejercicio de los derechos.

Este estado de cosas será infructuoso sin la voluntad individual del desarrollo moral de la persona, o sea, su responsabilidad convencida, su empatía y la toma autónoma de decisiones frente a los dilemas morales.

No hay que abundar en argumentos; los actores sociales y políticos, sobre todo estos últimos, han elegido instrumentos jurídicos frente al desafío de la paz; por el contrario, aquellos primeros han querido con la presentación del programa "soy capaz" en septiembre de 2014, proponer a los colombianos la necesidad de la reconciliación y de asumir desde lo cotidiano nuevas actitudes para dirimir los conflictos en los que se descarte cualquier expresión de violencia. Para ello se vincularon 120 empresas del país, medios de comunicación, equipos de balompié, artistas, la Iglesia católica y otras religiones. El programa incluyó 5 
pasos por internalizar: 1 . Soy capaz de reconocer que tenemos un problema y que el país puede estar mejor; 2 . Soy capaz de aceptar que soy parte del problema y también de la solución; 3. Soy capaz de ponerme en los zapatos de los demás; 4 . Soy capaz de entender que es más lo que nos une de lo que nos separa; 5 . Por mi futuro, por mi familia y por mi país soy capaz [...] para demostrar que la paz carece de dueño y que es un derecho fundamental de todos los colombianos (Portafolio, 2014, párr. 1 y 8).

Prera Flores (1997) señala que a "nivel del individuo, el movimiento comience en su interior. Esto supone incorporar a la paz como actitud de vida y proyectarla en la familia, la comunidad y las instituciones políticas" (p. 4), por ello, al ser humano se lo debe definir como capaz de transformar el mundo y su propia naturaleza. El hombre que ha creado la guerra y ha devenido en algo superior a sus fuerzas, hoy debe promover la unión de fuerzas capaces de influir en la población orientando su acción a la educación para la paz.

\section{Referencias}

Aragó, L. (20 de enero de 2019). El mapa de las guerras que siguen activas este 2019. La Vanguardia. https://www.lavanguardia.com/internacional/20190120/454204868905/ mapa-guerras-2019.html

BBC News (2018, 3 de mayo). Cuáles son los 10 países del mundo que gastan una mayor parte de su riqueza en armamento. https://www.bbc.com/mundo/noticias-internacional-43984570

Camps, V. (1994). Los valores de la educación. Grupo Anaya.

Clement, M. (1973). Guerra Subversiva y Guerra Revolucionaria. Revista Verbo, (113), 265286. http://www.fundacionspeiro.org/verbo/1973/V-113-P-265-286.pdf

Congreso de Colombia (2014, 1 de septiembre). Ley 1732. Por la cual se establece la Cátedra de la Paz en todas las instituciones educativas del país. Diario Oficial 43261. https:// www.funcionpublica.gov.co/eva/gestornormativo/norma.php? $\mathrm{i}=59313$

Cortina, A., y Conill, J. (1998). Democracia participativa y sociedad civil. Siglo del hombre editores.

La Vanguardia (2019, 8 de abril). Las claves del conflicto armado en el este de Ucrania. https:// www.lavanguardia.com/internacional/20190408/461527958033/las-claves-del-conflictoarmado-en-el-este-de-ucrania.html 
Lind, W. (2005). Comprendiendo la Guerra de cuarta generación. Military Review, Enero - Febrero, 12-17. http://geopolitica.iiec.unam.mx/sites/default/files/2018-08/Lind_comprendiendo\%20la\%20guerra\%20de\%20cuarta\%20generacio\%CC\%81n.pdf

Ministerio de Educación Nacional. (2015, 25 de mayo). Decreto 1038. Por el cual se reglamenta la Cátedra de la Paz. Diario Oficial 49522. https://www.funcionpublica.gov.co/eva/ gestornormativo/norma.php?i $=61735$

Ministerio de Educación Nacional. (2006). Plan nacional decenal de educación 2006 -2016. http://www.plandecenal.edu.co/cms/media/herramientas/pnde_2006_2016_cartilla.pdf

Ministerio de Educación Nacional. (2004). Formar para la ciudadanía iSí es posible! Estándares básicos de competencias ciudadanas - Lo que necesitamos saber y saber hacer. https://www.mineducacion.gov.co/1759/articles-75768_archivo_pdf.pdf

Organización de las Naciones Unidas (ONU). (2019, 8 de julio). El homicidio causa muchas más muertes que los conflictos armados, según nuevo estudio de la UNODC. https://www. unodc.org/unodc/es/frontpage/2019/July/el-homicidio-causa-muchas-ms-muertes-quelos-conflictos-armados--segn-nuevo-estudio-de-la-unodc.html

Pinna, M. (2019, 11 de julio). 18 años de guerra en Afganistán: 147.000 muertos. Euronews. https://es.euronews.com/2019/07/11/18-anos-de-guerra-en-afganistan-147-000-muertos

Presidencia de la República de Colombia. (2015, 25 de mayo). Decreto 1038. Por el cual se reglamenta la Cátedra de la Paz. Diario Oficial 49522. https://www.funcionpublica.gov. co/eva/gestornormativo/norma_pdf.php?i $=61735$

Prera Flores, A. (1997). La cultura de paz, un nuevo contrato moral de la sociedad. Unesco.

Portafolio. (2014, 9 de septiembre). Lanzan campaña 'Soy Capaz'. https://www.portafolio. co/economia/finanzas/lanzan-campana-capaz-48656

Sancha, N. (2018, 13 de marzo). Más de 500.000 muertos en siete años de guerra en Siria. El País. https://elpais.com/internacional/2018/03/12/actualidad/1520865451_577510.html

Zorro Sánchez, C. (2010, 6 de noviembre). Ética y politica en la coyuntura colombiana 1. https://evangelizadorasdelosapostoles.wordpress.com/2010/11/06/etica-y-politica-enla-coyuntura-colombiana1/

Unicef. (2018, 11 de mayo). República Democrática del Congo: en Kasai, 1 de cada 10 niños con desnutrición grave. https://www.unicef.es/noticia/republica-democratica-del-congoen-kasai-1-de-cada-10-ninos-con-desnutricion

Unidad para la atención y reparación integral a las víctimas. (2019). Víctimas del conflicto armado. https://www.unidadvictimas.gov.co/es/registro-unico-de-victimas-ruv/37394 